ECCOMAS

Proceedia
COMPDYN 2021

$8^{\text {th }}$ ECCOMAS Thematic Conference on Computational Methods in Structural Dynamics and Earthquake Engineering

M. Papadrakakis, M. Fragiadakis (eds.)

\title{
ROLE OF REPEATED SEISMIC EVENTS ON THE COLLAPSE OF TWO CALIDARIA IN ROME DATING BACK TO THE IMPERIAL AGE
}

\author{
Francesca Faleri ${ }^{1}$, Nicola Grillanda ${ }^{1}$, Selman Tezcan ${ }^{2}$, Renato Perucchio ${ }^{2}$, Gabriele \\ Milani $^{1}$
}

${ }^{1}$ Department of Architecture, Built Environment and Construction Engineering (ABC), Polytechnic University of Milan

Piazza Leonardo Da Vinci 32, 20133 Milan (Italy)

email: francescafaleri2@gmail.com,nicola.grillanda@polimi.it, gabriele.milani@polimi.it

${ }^{2}$ Department of Mechanical Engineering, University of Rochester, Rochester, NY, USA email: stezcan@ur.rochester.edu,rlp@me.rochester.edu

\begin{abstract}
The seismic assessment of two vaulted monuments made of Roman concrete is here presented. Both their structural forms and constituent materials are here explored, whose combination enabled to build such largescale structures, and whose knowledge is essential for assessing and maintaining the safety of the portions of such structures that still exist.

Specifically, two different monuments dating back to the Imperial age are analyzed: the Calidarium of the Baths of Caracalla and the Calidarium of the Diocletian's Baths. The two structures were built at a distance of less than one century one each other and both were erected with the same construction technique. Nowadays both Calidarium structures no longer exist: the first one still presents two not collapsed monumental pillars, whilst the ruins of the second were demolished in the Sixteenth Century. Therefore, the present work aims at investigating the causes behind their collapse and how their collapse occurred by performing advanced numerical simulations.
\end{abstract}

Keywords: seismic assessment, vaulted monuments, roman concrete, monuments, Imperial age, structural analyses.

ISSN:2623-3347 C 2021 The Authors. Published by Eccomas Proceedia.

Peer-review under responsibility of the organizing committee of COMPDYN 2021.

doi:10.7712/120121.8494.19238 


\section{INTRODUCTION}

Roman vaulted structures belonging to the imperial age represent one of the most important contributions to the artistic, architectural and engineering heritage of the entire world and their extraordinary durability is an aspect that should make the whole scientific community reflect and inspire. These large spans and curvilinear forms are still visible in buildings such as the Pantheon, the thermal baths of Caracalla and Diocletian, the Trajan's Markets and the Basilica of Maxentius, but these are just some of the many monuments still preserved in an impressive way. The secret of the majesty of these monuments and their longevity lies in the combination of the use of monumental vaulted forms and Roman concrete [1].

Caracalla's and Diocletian's Calidaria were two of the largest vaulted structures built with unreinforced pozzolanic Roman concrete. The high complexity of such constructions requires advanced numerical techniques to be analyzed. The characteristics of the Roman concrete, poor tensile resistance compared with high compressive strength, provide it a quasi no-tension behavior [2] allowing to follow the numerical strategies proposed for vaulted masonry structures [3]. Among the methods currently available from the technical literature, we can mention the modern limit analysis tools based on the static [4-6] and the kinematic theorem [7-12] but also the recent numerical techniques relying on the Finite Element (FE) method [13-16].

In this paper, a numerical investigation behind the causes of the collapse of these vaulted structures is conducted. The seismic vulnerability is studied through non-linear dynamic simulations carried out on FE models in the software Abaqus/CAE, where the behavior of the pozzolanic concrete (opus caementicium) is represented by means of the concrete damage plasticity model [17] available within Abaqus. Finally, non-linear time-history analyses are carried out on both structures by applying an accelerogram compatible with the response spectrum of Rome.

\section{ABOUT ROMAN CONCRETE "OPUS CAEMENTICIUM"}

The material used in vaulted monuments such as Caracalla and Diocletian Baths consists in a composite masonry structure, called opus latericium, made of two external brick walls with a triangular shape and a concrete core composed by a pozzolanic lime mortar containing large pieces of stone, brick, marble and tufa (opus caementicium). The distribution of materials with decreasing density are observed: a distinct gradation of brick in the lower third (1800 $\left.\mathrm{kg} / \mathrm{m}^{3}\right)$, tufo lionato in the middle third $\left(1600 \mathrm{~kg} / \mathrm{m}^{3}\right)$, and Vesuvian scoria in the upper third $\left(1400 \mathrm{~kg} / \mathrm{m}^{3}\right)$.

The mechanical characterization of the Roman concrete was possible thanks to the analysis of the results obtained from a consistent test campaign carried out at the University of Rome "La Sapienza" (1996) and conducted by A. Samuelli Ferretti [18]. According to the experimental results, the elastic parameters adopted in the structural analyses are: elastic modulus $\mathrm{E}$ $=3000 \mathrm{MPa}$, Poisson modulus $\mathrm{v}=0.5$, compression strength $\mathrm{fc}=5 \mathrm{MPa}$ and tensile strength $\mathrm{ft}=0.5 \mathrm{MPa}$. Post elastic non-linear behavior is taken into account through the Concrete Damaged Plasticity Model. Damage plasticity is a continuum macro-model for concrete, originally developed by Lubliner et al. [17] and modified by Lee and Fenves [19], which incorporates tensile cracking and compressive crushing as the primary failure mechanisms. Moreover, it assumes the fracture energy formulation for concrete developed in [20]. Regarding the postelastic behavior on the Roman concrete, an innovative study was performed at the University of Rochester by Ivancic, Brune and Perucchio [21] which allowed to construct a nonlinear damage plasticity formulation for both compressive and tensile response of the opus caementicium suitable for 3D implementation in Abaqus (see Figure 1). 


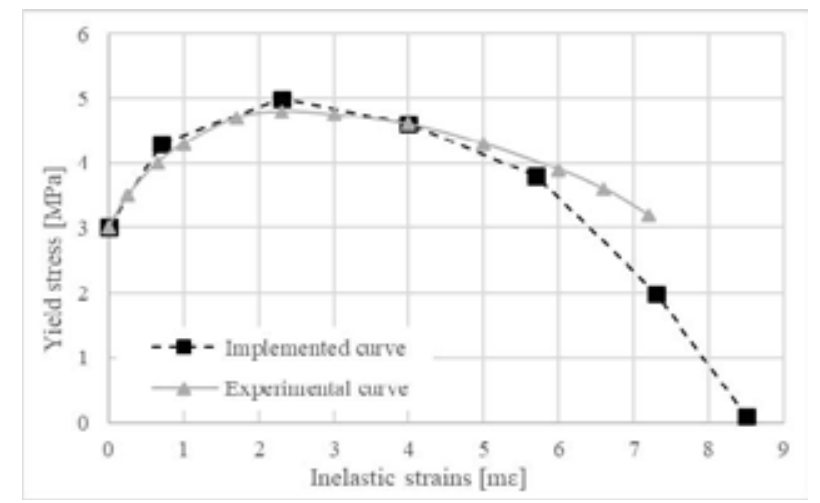

\begin{tabular}{|c|c|c|c|c|c|c|c|}
\hline Yield stress [MPa] & 3 & 4.3 & 5 & 4.6 & 3.8 & 2 & 0.1 \\
\hline Inelastic strains [10 $\left.0^{-3}\right]$ & 0 & 0.7 & 2.3 & 4 & 5.7 & 7.3 & 8.5 \\
\hline Damage Variable & 0 & 0.2 & 0.25 & 0.4 & 0.5 & 0.7 & 0.98 \\
\hline
\end{tabular}

(a)

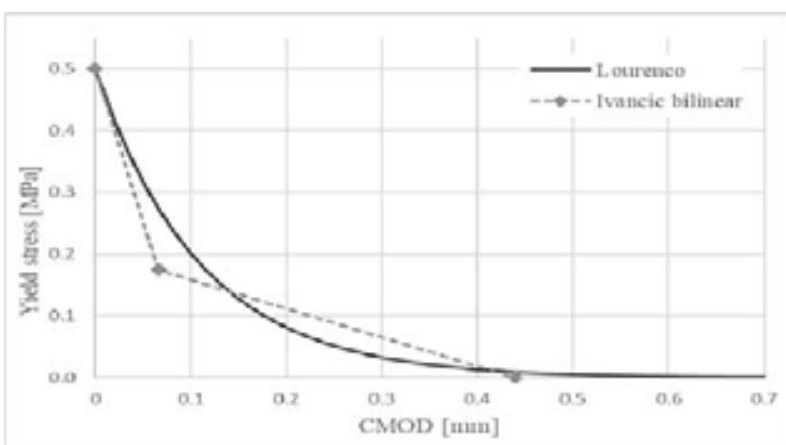

\begin{tabular}{|c|c|c|c|c|c|c|c|c|c|c|c|c|c|c|c|c|}
\hline Yield stress [MPa] & 0.500 & 0.398 & 0.317 & 0.253 & 0.202 & 0.160 & 0.128 & 0.081 & 0.052 & 0.033 & 0.021 & 0.008 & 0.005 & 0.003 & 0.002 & 0.001 \\
\hline CMOD [mm] & 0 & 0.025 & 0.050 & 0.075 & 0.125 & 0.150 & 0.200 & 0.250 & 0.300 & 0.350 & 0.400 & 0.450 & 0.500 & 0.550 & 0.600 & 0.7 \\
\hline Damage Variable & 0 & 0.1 & 0.2 & 0.3 & 0.4 & 0.45 & 0.5 & 0.55 & 0.6 & 0.65 & 0.7 & 0.75 & 0.8 & 0.85 & 0.9 & 0.98 \\
\hline
\end{tabular}

(b)

Figure 1: Non-linear (a) compression and (b) tension damage-plasticity model implemented in Abaqus for the Roman concrete (where CMOD stands for Crack Mouth Opening Displacement).

\section{NON-LINEAR DYNAMIC ANALYSIS OF TWO CALIDARIA IN ROME}

The dynamic non-linear analysis of the Calidaria of the Baths of Caracalla (216 A.D.) and the Baths of Diocletian (306 A.D.) are here presented.

The Calidarium of the Caracalla's baths (see Figure 2) was a circular room paved in marble and roofed with a dome of almost $36 \mathrm{~m}$ diameter, very similar to the dimension of the Pantheon. The weight of the dome was carried by eight pillars made in Roman concrete. The plan view shows a structure composed of an internal diameter of $36 \mathrm{~m}$ and pillars with a thickness of $6 \mathrm{~m}$ (1/6 of the external radius). Two levels of vaults can be observed from the cross-sections. The first one consists of vaults whose springers are located at a height of $11 \mathrm{~m}$ from the ground; conversely, those at the upper level have a particular shape that maximizes the light entering the structure. The thickness of the dome at the crown is assumed to be equal to $1.5 \mathrm{~m}$, as in the dome of the Pantheon. 


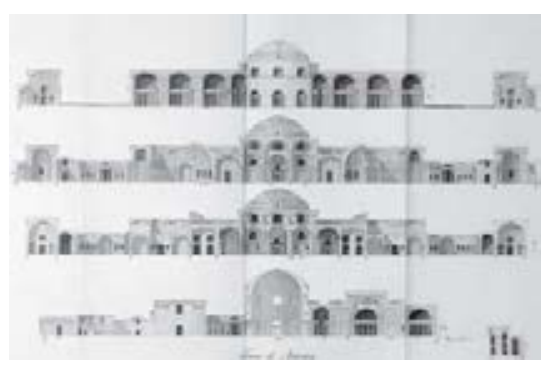

(a)

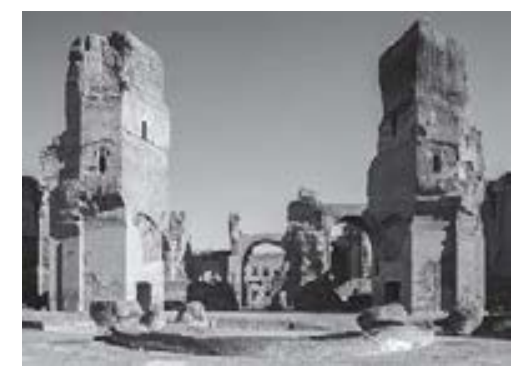

(b)

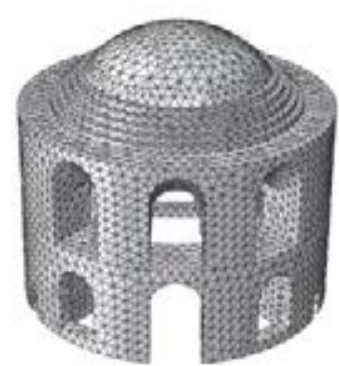

(c)

Figure 2: Baths of Caracalla: (a) drawings made by Palladio, (b) current state of the Calidarium, and (c) FE model.

By following the prescriptions given by the regional authority (Regione Lazio), an appropriate accelerogram compatible with the response spectrum was adopted and applied in both directions ( $\mathrm{x}$ and $\mathrm{y}$ ). The shape and the duration of the seismic input can be observed in Figure 3. Three meaningful instants indicated through the points $\mathrm{A}, \mathrm{B}$, and $\mathrm{C}$, are defined in the accelerogram and highlighted in the results.

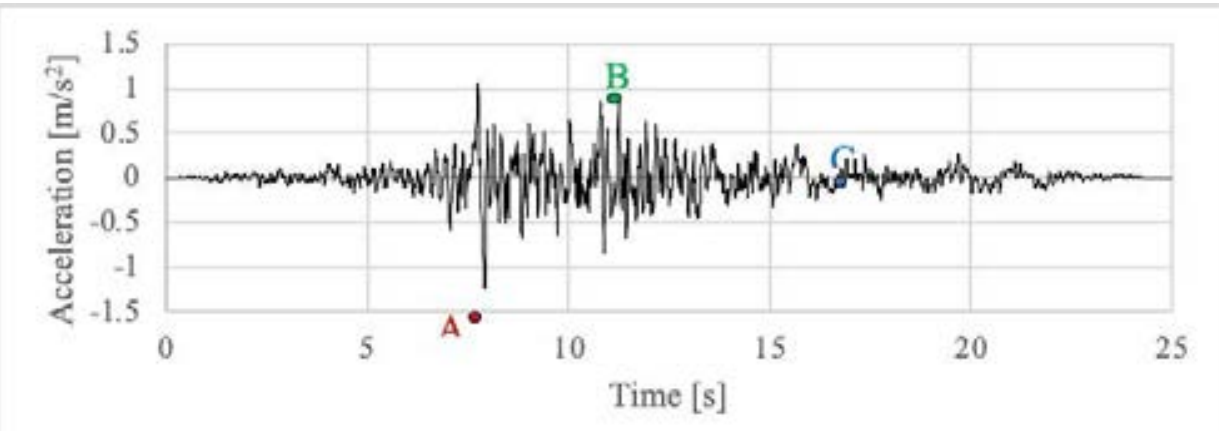

Figure 3: Accelerogram adopted in the dynamic non-linear analyses (points $\mathrm{A}: \mathrm{t}=7.9 \mathrm{~s}, \mathrm{~B}: \mathrm{t}=11.3 \mathrm{~s}, \mathrm{C}: \mathrm{t}=$ $17 \mathrm{~s})$.

The level of damage suffered by the Calidarium is represented in terms of plastic strains in the different time instants, see Figure 4. The dark areas indicate the presence of plastic strains generated by traction, therefore they correspond to the areas where tensile cracks develop.

As it can be observed from Figure 4, after the first peaks of the accelerogram (point A), high plastic strains develop within the structure: fracture lines propagate from the vaults up to the top of the dome.

Figure 5 shows the trend of the strain energy and plastic dissipation energy during the analysis. It can be observed that point A (i.e. peak value of the accelerogram) coincides with the instant in which the plastic dissipation energy begins to increase, while in point $\mathrm{C}$ it has already assumed its final value. At the end of the analysis, the plastic dissipation energy and the strain energy have almost the same value. The energy plastically dissipated at the end of the strongest part of the accelerogram reaches a sort of plateau and its value remains stable until the end of the analysis. Therefore, it can be supposed that an accumulation of damage has been generated in the Calidarium but that the seismic action is not sufficient to cause the failure of the dome. Therefore, it can be stated that the collapse of the Calidarium is not associated with a single seismic event, but probably is due to the repetition of multiple earthquakes. 


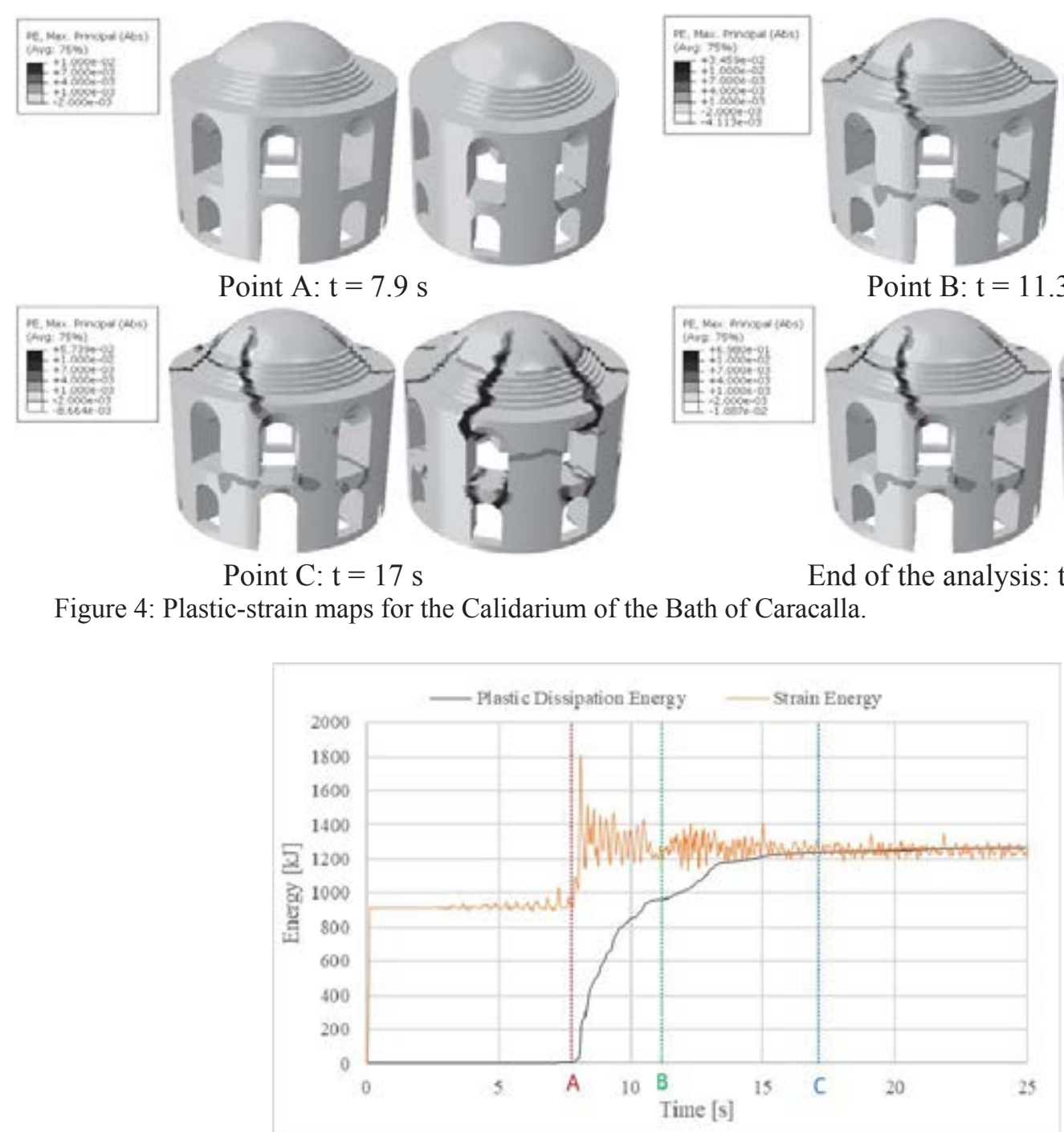

Figure 5: Internal energy-time diagrams (accelerogram applied along both directions).

The Baths of Diocletian, see Figure 6, represent the largest thermal complex ever built in ancient Rome. Its Calidarium was a rectangular room paved in marble and roofed by a system of three cross vaults. The entire structure was made in Roman concrete with the exception of the entablature blocks and granite columns on which the cross vaults rested. Moreover, there were three lateral apses, also supported by granite columns. Nowadays only a small portion of the north-eastern side of the Calidarium is still standing (Figure 6b).

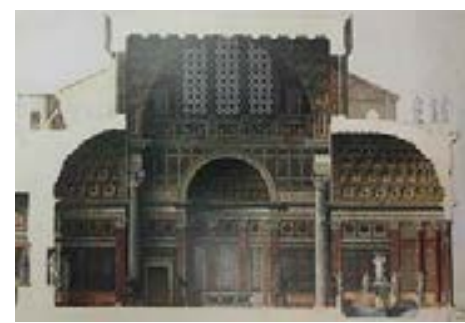

(a)

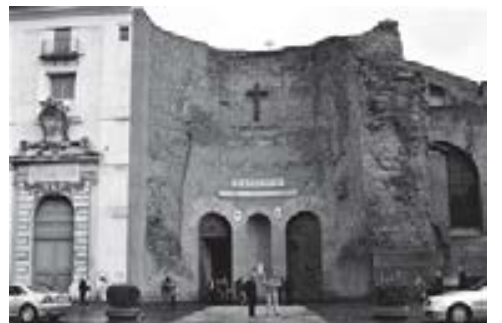

(b)

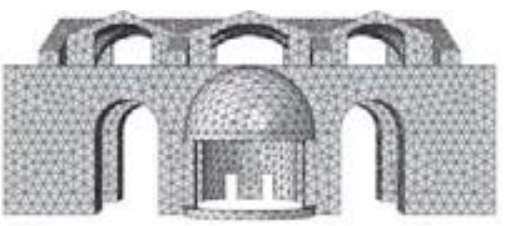

(c)

Figure 6: Baths of Diocletian: (a) transversal cross-section of the Calidarium (E. Paulin, 1880), (b) current state, and (c) FE model 
The results of the non-linear dynamic analysis here presented are obtained by considering the same accelerogram used for the Calidarium of Caracalla (Figure 3) and applying it in both $\mathrm{x}$ and $\mathrm{y}$ directions. The analysis stops before the ending of the duration time of the accelerogram due to the collapse of the front apse that provoked the excessive distortion of the elements of the mesh. By observing the derived crack patterns depicted in Figure 7, the Calidarium appears totally intact, except for the front apse that at the time instant $\mathrm{C}$ presents a high level of plastic strains.

The trend of the internal energies evaluated in the roof of the Calidarium and in its central apse are reported in Figure 8. While the energy plastically dissipated in the roof is very low, in the apse it reaches very high values (Figure 8b). This result demonstrates that the collapse of the apse occurs before the roof suffers high damages. Deduction that is completely in accordance with the ruins of the structure represented in the drawing made by Dosio (15331611).

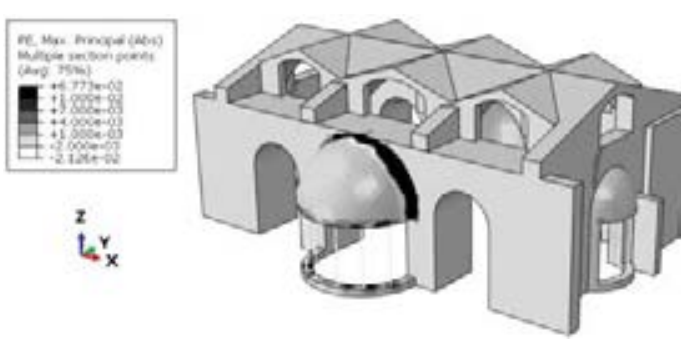

Point A: $\mathrm{t}=7.9 \mathrm{~s}$

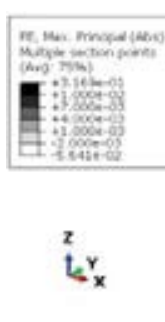

Point B: $\mathrm{t}=11.3 \mathrm{~s}$

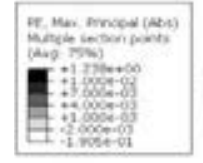

$\operatorname{los}_{x}^{x}$

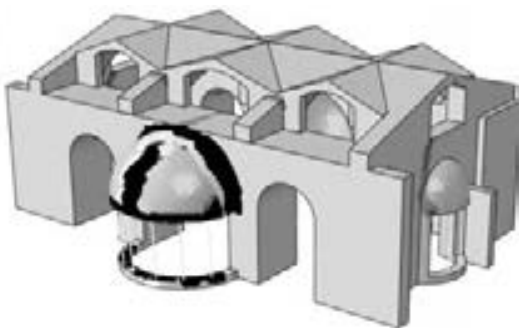

Point $\mathrm{C}: \mathrm{t}=17 \mathrm{~s}$

Figure 7: Plastic strain maps for the Calidarium of Diocletian. 


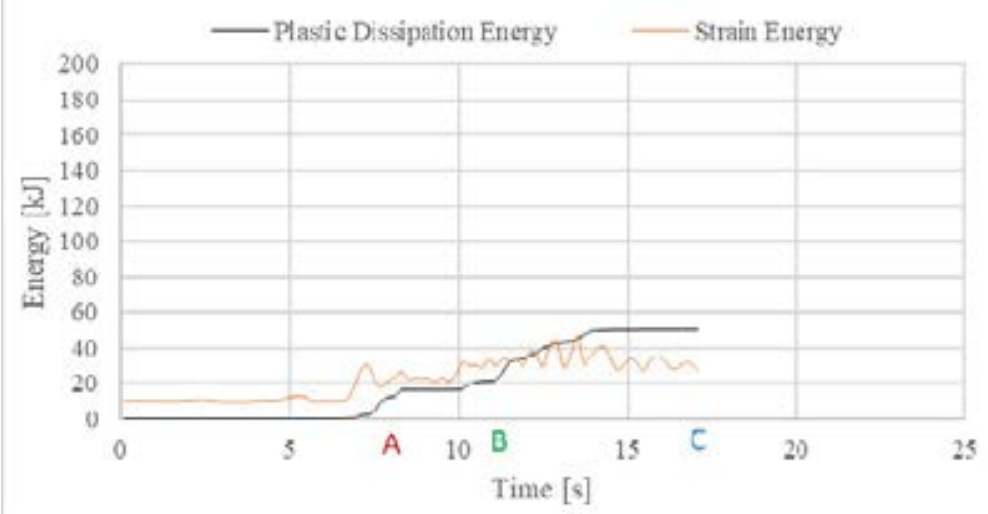

(a)

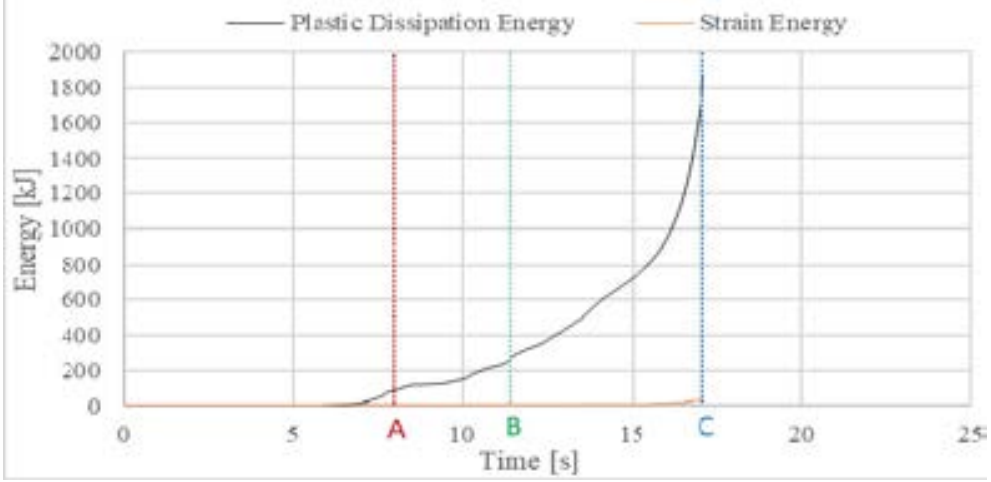

(b)

Figure 8: Internal energy-time diagrams: (a) roof and (b) apse.

\section{CONCLUSIONS}

In this paper, the collapse of two Roman concrete Calidaria in Rome has been investigated by means of advanced non-linear dynamic analyses performed in Abaqus. The behavior of the Roman concrete, the so-called opus caementicium, is represented by means of the concrete damage plasticity model. A non-linear damage plasticity law for both compressive and tensile response of the opus caementicium has been implemented in Abaqus to correctly reproduce the post-elastic behavior.

As far as the Calidarium of the Caracalla's Baths is concerned, the application of a single accelerogram is not sufficient to generate its collapse condition. However, at the end of the dynamic analysis, high plastic strains develop within the structure, indicating that the application of a further accelerogram may cause the collapse of its dome. Therefore, it can be argued that the seismic events occurring in Rome over the course of its post-Imperial history generated damages that had accumulated within the structure, greatly reducing its resistance. Consequently, the collapse may have occurred during or after one of those seismic events, just when the structure itself was already damaged.

The analyses carried out on the Calidarium of the Diocletian's Baths show that the front apse is the first structural part to have collapsed. Despite how reported by Dosio in its drawings, in which the Calidarium is represented without its front apse and its roof, at the end of the dynamic analysis the upper cross vaults appear poorly damaged.

Eventually, for both Calidaria it has been discovered that their collapse is not associated with a single seismic event, but with the repetition of multiple earthquakes. 


\section{REFERENCES}

[1] L.C. Lancaster, Concrete Vaulted Constructions in Imperial Rome: Innovations in Context, New York: Cambridge University Press, 2005.

[2] J. Heyman, The stone skeleton. International Journal of Solids and Structures, 2, 249$56,1966$.

[3] A. Tralli, C. Alessandri and G. Milani, Computational methods for masonry vaults: A review of recent results. Open Civil Engineering Journal, 8, 272-87, 2014.

[4] P. Block P and J. Ochsendorf, Thrust network analysis: A new methodology for threedimensional equilibrium. Journal of the International Association for shell and spatial structures, 48, 1-7, 2007.

[5] F. Marmo and L. Rosati, Reformulation and extension of the thrust network analysis. Computers \& Structures, 182, 104-18, 2017.

[6] N.A. Nodargi and P. Bisegna, Thrust line analysis revisited and applied to optimization of masonry arches. International Journal of Mechanical Sciences, 179(105690), 2020.

[7] E. Milani, G. Milani and A. Tralli, Limit analysis of masonry vaults by means of curved shell finite elements and homogenization. International Journal of Solids and Structures, 45, 5258-88, 2008.

[8] M. Pavlovic, E. Reccia and A. Cecchi, A Procedure to Investigate the Collapse Behavior of Masonry Domes: Some Meaningful Cases. International Journal of Architectural Heritage, 10, 67-83, 2016.

[9] A. Chiozzi, G. Milani and A. Tralli, A Genetic Algorithm NURBS-based new approach for fast kinematic limit analysis of masonry vaults. Computers \& Structures 182, 187-204, 2017.

[10] N., Grillanda, A. Chiozzi, G. Milani and A. Tralli, Collapse behavior of masonry domes under seismic loads: an adaptive NURBS kinematic limit analysis approach. Engineering Structures, 200(109517), 2019.

[11] N. Grillanda, M. Valente, G. Milani, A. Chiozzi and A. Tralli, Advanced numerical strategies for seismic assessment of historical masonry aggregates. Engineering Structures, 212(110441) 2020.

[12] N. Grillanda, M. Valente and G. Milani, ANUB-Aggregates: a fully automatic NURBS-based software for advanced local failure analyses of historical masonry aggregates. Bulletin Earthquake Engineering, 18, 3965-61, 2020.

[13] J. Scacco, G. Milani and P.B. Lourenço, Automatic mesh generator for the non-linear homogenized analysis of double curvature masonry structures. Advanced Engineering Software, 150(102919), 2020.

[14] J. Scacco, B. Ghiassi, G. Milani and P.B. Lourenço, A fast modeling approach for numerical analysis of unreinforced and FRCM reinforced masonry walls under out-ofplane loading. Composites Part B: Engineering, 180(107553), 2020.

[15] J. Scacco, G. Milani and P.B. Lourenço, A micro-modeling approach for the prediction of TRM bond performance on curved masonry substrates. Composites Structures, 256(113065), 2021.

[16] M. Valente, G. Milani, E. Grande and A. Formisano, Historical masonry building 
aggregates: advanced numerical insight for an effective seismic assessment on two row housing compounds. Engineering Structures, 190, 360-79, 2019;190:360-79.

[17] J. Lubliner, J. Oliver, S. Olle and E. Onate, A Plastic-Damage Model for Concrete. International Journal of Solids and Structures, 25, 299-326, 1989.

[18] A. Saumelli Ferretti, Materiali da costruzione e tecnologie costruttive del patrimonio archeologico e monumentale romano Unpublished research conductued at Università degli Studi di Roma "La Sapienza", 1996.

[19] J. Lee and G. L. Fenves, Plastic-Damage Model for Cyclic Loading of Concrete Structures. Journal of Engineering Mechanics, 124, 892-900, 1998.

[20] M. Modéer, P. Petersson and A. Hillerborg, Analysis of crack formation and crack growth in concrete by means of fracture mechanics and finite elements. Cement and Concrete Research, 6(6), 773-82, 1976.

[21] P. Brune, R. Perucchio and S. Ivancic, A Concrete Damage Plasticity Model fo Ancient Roman Pozzolanic Concrete. 9th International Masonry Conference, Guimarães, Portugal, 7-9 July 2014. 